\title{
Osteology of the first dorsal fin in two terapontid fishes, Leiopotherapon unicolor (Günther, 1859) and Amniataba caudavittata (Richardson, 1845), from Western Australia: evidence for hybridisation?
}

\author{
David L. Morgan and Howard S. Gill \\ Centre for Fish and Fisheries Research, Murdoch University, South Street, Murdoch, \\ Western Australia 6150, Australia; Email: d.morgan (murdoch.edu.au
}

\begin{abstract}
Osteological characters, such as number of supraneural bones anterior to first neural spine, number of spines on first dorsal pterygiophore, position of insertion of first proximal dorsal pterygiophore and number of anterior proximal dorsal pterygiophores inserting between successive neural spines, in conjunction with morphological characters, were used to provide evidence of natural hybridisation between two species of the Terapontidae: the freshwater Leiopotherapon unicolor and the marine/estuarine Amniataba caudavittata.
\end{abstract}

\section{INTRODUCTION}

The Terapontidae (commonly called trumpeters or grunters) consists of small to medium-sized fishes represented by approximately 46 species from 16 genera in marine and freshwaters of the Indo-Pacific region (Vari 1978; Nelson 1994; Allen et al. 2002). Of these, about 33 are restricted to the freshwaters of New Guinea and Australia where they are often of economic and/or recreational importance (Allen et al. 2002). The 16 genera assigned to the group are separated on the basis of the following features: pigmentation; extrinsic swimbladder muscle; swimbladder and intestinal pattern; height of dorsal and anal fin sheath; and osteological characteristics of the posttemporal, tabular, dentary, maxilla, premaxilla, spinous dorsal fin and vertebral column (Vari 1978). The Australian terapontid fauna consists of 25 species which are restricted to treshwaters and a further eight species that are considered predominantly marine or estuarine (Vari 1978; Allen et al. 2002).

Two of the most common and widespread terapontids in Australia are the Spangled Perch Leiopotherapon unicolor (Günther, 1859) and the Yellowtail Trumpeter Amniataba caudavittata (Richardson, 1845). The former is the most widespread freshwater fish species in Australia, occurring in major rivers, isolated drainages and ponds throughout the northern two thirds of Australia, including most river systems north of the Murchison River in Western Australia, the Northern Territory, Queensland, the Lake Eyre/ Bulloo drainage systems and those rivers north of the Murray-Darling River in New South Wales (Vari 1978; Allen et al. 2002). Amniataba caudarittata occurs from the lower west coast of
Western Australia, throughout northern Australia and southern New Guinea to the east coast of northern Queensland (Vari 1978; Allen et al. 2002). Whilst $A$. caudavittata is considered to be primarily marine (Vari 1978), in south-western Australia it is essentially restricted to estuaries (Potter et al. 1994; Wise et al. 1994). It is also able to tolerate both freshwater and hypersaline conditions (Hutchins and Swainston 1986; Morgan and Gill 2004).

Leiopotherapon unicolor and $A$. caudavittata both attain total lengths of ca $300 \mathrm{~mm}$ and are superficially similar, with considerable overlap occurring in many of the characteristics often used to differentiate between species of fish, e.g., dorsalfin spines (XI-XIII in L. unicolor cf. XII-XIII in A. caudavittata); dorsal-fin rays ( $9-12$ cf. 8-10); anal-fin rays (III, 7-10 cf. III, 8-9); pectoral-fin rays ( $15-16 \mathrm{cf}$. 13-17); pelvic-fin rays (both I-5); lateral line scales (45-57 cf. 46-54); scales above lateral line (both 7-9); scales below lateral line (16-20 cf. 17-19); caudal scales (3-6 cf. 4-6); and predorsal scales to occiput (15-20 cf. 14-17) (Vari 1978). Notwithstanding the above similarities in these species, $L$. unicolor is readily distinguished from $A$. caudavittata as the fins of the former species are a uniform pale, silvery-grey colour, whereas those of the latter species are yellow and, in the case of the $2^{\text {nd }}$ dorsalfin and caudal-fin, bear prominent black bands (Vari 1978). Furthermore, in L. unicolor the row of spots running from the eye to the upper jaw and the row below the eye from the preopercle to the upper jaw are represented by distinct spots, whereas in smaller specimens of A. caudavittata these spots coalesce to form two distinct bands (see Figure 1 and photographs on pages 227 and 241 in Allen et al. 2002) 

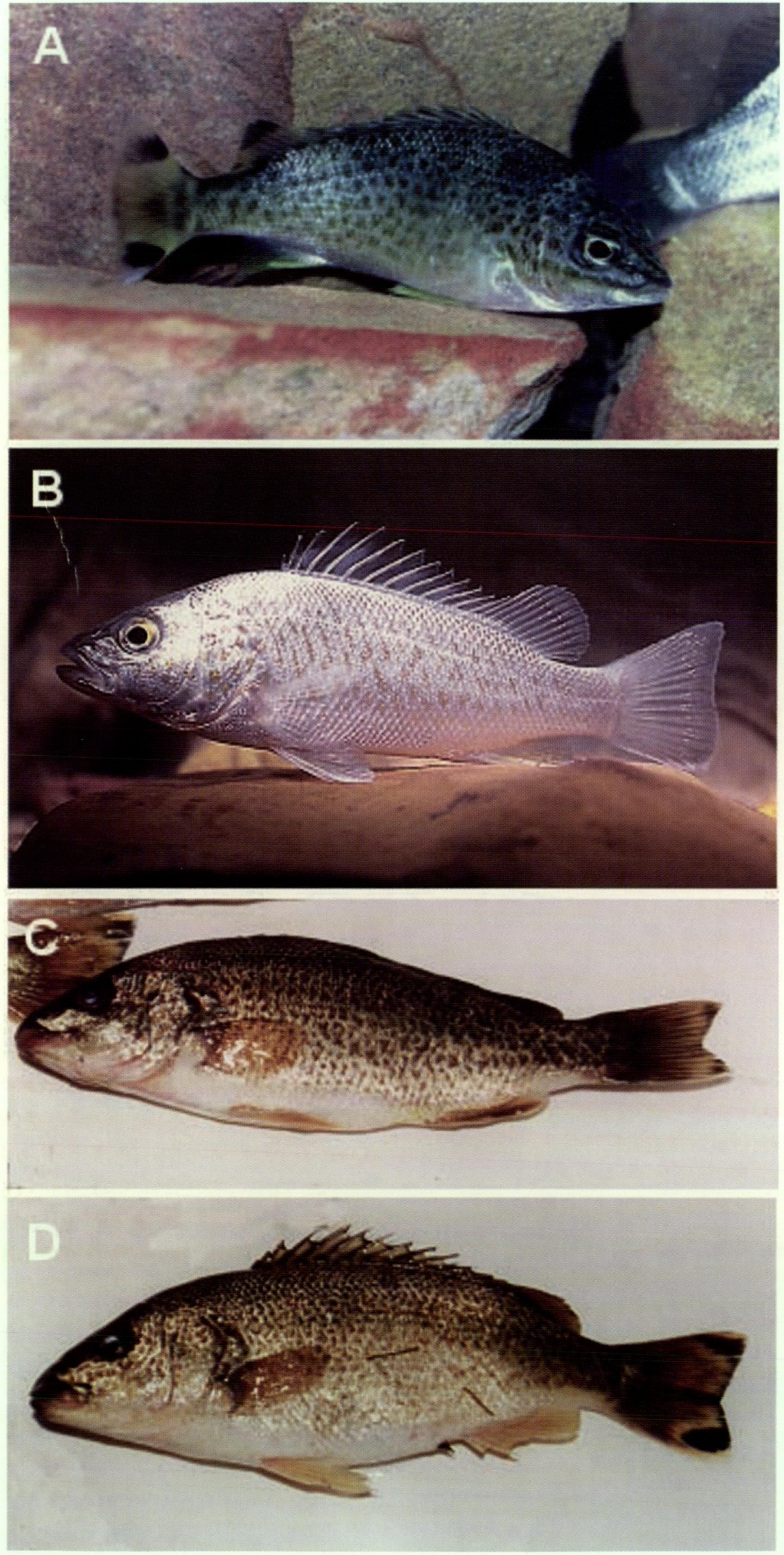

Figure 1 A, Amniataba caudavittata. B, Leiopotherapon unicolor and C and D, intermediate forms (note bars on caudal fins and rounded snout). 
In addition to the clear distinction in coloration between $L$. unicolor and $A$. caudavittata, members of the genus Leiopotherapon can be differentiated from those of Amniataba using the following osteological criteria: one supraneural bone in front of the first neural spine in Leiopotherapon compared to two in Amniataba; one spine on first dorsal pterygiophore cf. two; the insertion of the first proximal dorsal pterygiophore between the second and third neural spines cf. its insertion between the first and second; two of the anterior proximal dorsal pterygiophores inserting between successive neural spines cf. one (Figure 2) (Vari 1978).

During a recent survey of the freshwater fishes of the Pilbara (Morgan and Gill 2004) L. unicolor and A. caudavittata were often observed schooling together up to $300 \mathrm{~km}$ inland in the Murchison River. On closer examination, it became apparent that many individuals from these mixed schools possessed combinations of coloration and pattern characteristic of both species. Thus, some individuals had distinct spots that had not coalesced into bands on the snout and cheek (characteristic of L. unicolor) but had yellowish fins (characteristic of A. caudavittata) and either had no, or one or two weak or strong band(s) on their caudal lobes (characteristics of either L. unicolor or A. caudavittata, or intermediate between the two) (see Figure 1). It was suspected that these individuals were hybrids.

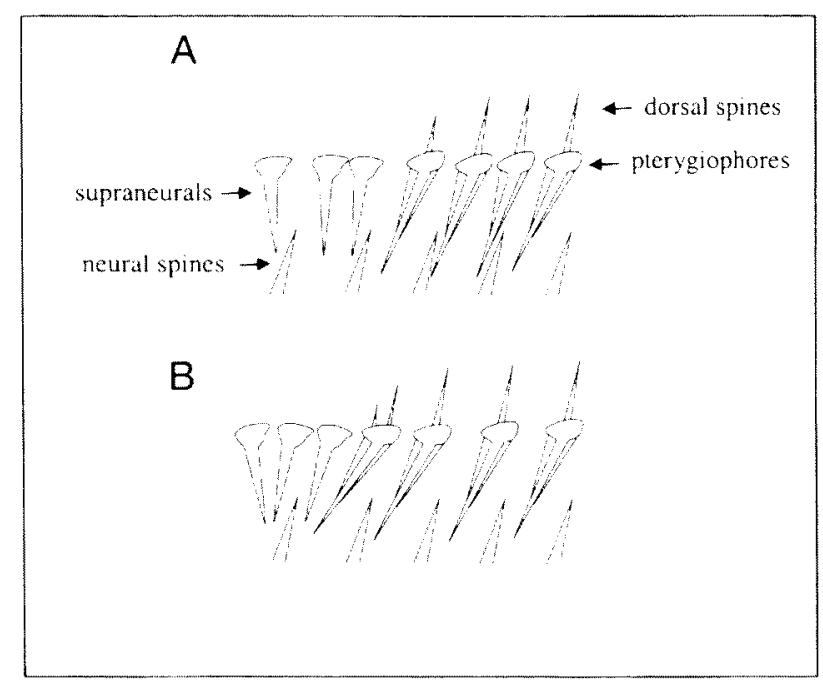

Figure 2 Diagramatic representation of the supraneurals, anterior proximal pterygiophores, anterior neural spines and anterior $1^{\text {th }}$ dorsal spines in $A$, Leiopotherapon and B, Amniataba. N.B. One supraneural anterior to first neural spine in Leiopotherapon (versus 2 in Amriataba); one dorsal spine on first anterior pterygiophore in Leiopotherapon (versus 2 in Amniataba); and second and third anterior pterygiophores inserting between successive neural spines in Leiopotherapon (from Vari 1978).
Hybridisation between fish species is not uncommon and Schwartz (1972, 1981) compiled almost 4000 references reporting either natural or artificial hybridisation between various species. Historically, the main methods of detecting hybrids have been through the comparison of morphological characters (e.g., morphometric and meristic data), with the assumption that the hybrid has characters that are intermediate between the parent species (Campton 1987, 1991). In this paper we describe the osteology of the first dorsal fin and, by comparison with the descriptions and diagnoses of the two genera provided by Vari (1978), provide evidence of natural hybridisation in the Terapontidae. In addition, we provide evidence to suggest that the hybrids are reproductively viable.

\section{MATERIALS AND METHODS}

\section{Murchison River, Western Australia}

The Murchison River is located in the Pilbara (or Indian Ocean) Drainage Division of Western Australia and is large by Western Australian standards, draining approximately $120000 \mathrm{~km}^{2}$ (Figure 3). Its headwaters arise near Meekatharra, approximately $500 \mathrm{~km}$ inland from the mouth at Kalbarri. Precipitation near the river mouth is relatively low and highly seasonal (mean ca 375 $\mathrm{mm}$ /annum), with low summer and medium winter falls, while the inland reaches receive relatively marginal and unpredictable rainfall (ca $238 \mathrm{~mm}$ / annum) throughout the year (data provided by the Western Australian Bureau of Meteorology). The river is marginally saline throughout its length.

\section{Sampling localities and environmental variables}

Thirteen sites on the lower, middle and upper Murchison River were sampled using a variety of seine nets and rod and line. The seine nets were comprised of either 3 or $6 \mathrm{~mm}$ woven mesh. The main study sites ( 3 and 4 ) were situated at the eastern end of the Kalbarri National Park (Figure 3) and the water temperature and conductivity were recorded in each month between December 2000 and November 2001 at site 4. Other sites were sampled on a single occasion and the numbers of each species (that superficially resembled either $L$. unicolor or A. caudavittata) were recorded and they were then released immediately. Fish that were kept were euthanased in an ice slurry.

\section{Morphology and osteology}

Each fish retained from the Murchison River was measured to the nearest $1 \mathrm{~mm}$ (total length) and a subjective assessment made as to whether the individual superficially resembled more closely $L$. unicolor or A caudavittata; based on fin and body 
coloration and patterning, and also overall shape (in $L$. unicolor the body is slender and the snout rounded, whereas the body of $A$. caudavittata is moderately deep and the snout pointed and relatively shorter than that of $L$. unicolor). The vertebral column, and associated supraneurals, pterygiophores and dorsal spines, below the anterior-most section of the first dorsal-fin were then displayed by dissection and the following characteristics determined: number of supraneurals in front of the first neural spine (one or two for Leiopotherapon and Amniataba, respectively); number of dorsal-fin spines (one or two) on first dorsal-fin pterygiophore; the position of the insertion of the first proximal dorsal-fin pterygiophore (between second and third or first and second neural spine); and number of anterior proximal dorsal-fin pterygiophores inserting between successive neural spines (one or two) (Vari 1978, and Figure 2). The vertebral column and associated structures were then drawn with the aid of a dissecting microscope and compared to those that comply with either L. unicolor or $A$. caudavittata (Vari 1978, and Figures 2 and 4). Dissection, rather than radiography, was used to determine the osteolgy of the first dorsal-fin as a

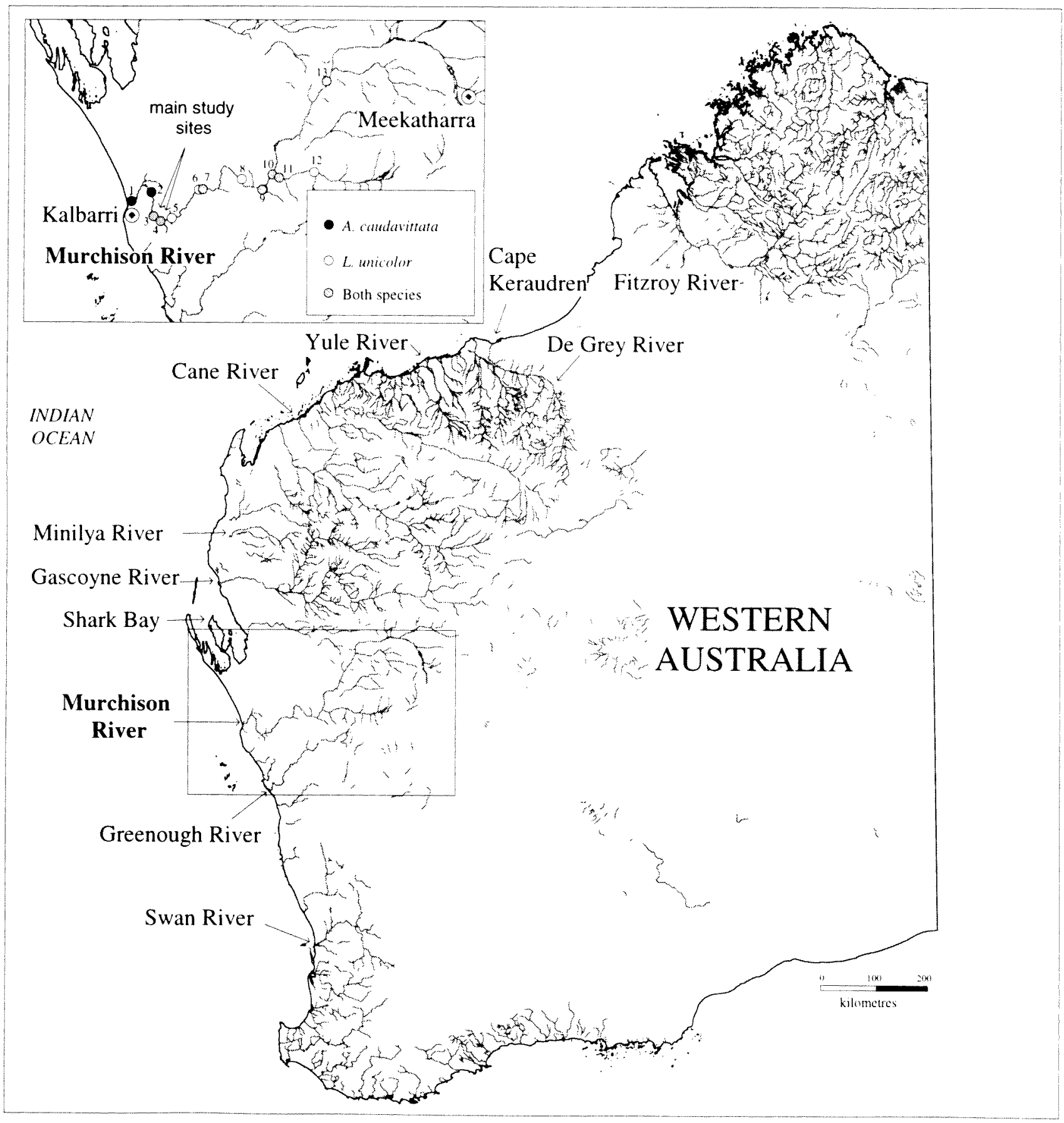

Figure 3 The rivers and embayments (Shark Bay) in Western Australia from which terapontids were examined. The main study sites on the Murchison Rivers, and the major towns, Kalbarri and Meekatharra, are also given. 
preliminary investigation demonstrated that radiographs were often difficult to interpret, whereas dissection provided unambiguous and accurate descriptions.

The osteology of individuals of presumptive $L$. unicolor from the Gascoyne ( 5 specimens), Minilya (4), Cane (5), Yule (5), De Grey (5) and Fitzroy (5) rivers, and $A$. caudavittata from the Swan River (5), Shark Bay (25) and Cape Keraudien (33) were also determined (Figure 3). Specimens of Leiopotherapon unicolor in the collections of the Western Australian Museum were also examined (P4336, 4, 56-83 mm TL, Murchison River, 12 October 1958; P5362, 3, 75-100 mm TL, Murchison River, Galena, 27 September 1961).

In order to determine whether a variant pattern (Figure 4) more closely resembled L. unicolor or A. caudavittata the minimum number of changes required to transform each individual pattern to that of $L$. unicolor and A. caudavittata was estimated. In these transformations the following assumptions were made. Firstly, in general, dorsal spines and pterygiophores were not independent, thus the loss, gain, or movement of an individual pterygiophore included a corresponding loss, gain or movement of the associated spine. Secondly, in the case of the first pterygiophore, it was considered that the loss of a second spine on that pterygiophore could occur without losing the pterygiophore and other spine, and that gaining a second spine on the first pterygiophore did not require gaining an additional pterygiophore bearing two spines. It is worth noting that if this second assumption is not made, and transformations require the loss (or gain) of the whole pterygiophore they contain either the same number of steps or require additional steps. Finally, where there are two or more equally short transformations, the one presented in Table 1 maximises movements rather than losses and gains, e.g., in Type 19 the transformation to Leiopotherapon presented is: Step 1, move supraneural 2 to between neural spines 1 and 2 ; Step 2, move supraneural 3 to between neural spines 1 and 2; Step 3, remove $1^{\text {st }}$ pterygiophore; Step 4, remove $2^{\text {id }}$ or $3^{\text {rd }}$ pterygiophore; Step 5, move new pterygiophore 1 to between neural spines 2 and 3; Step 6, move new pterygiophore 2 to between neural spines 3 and 4 . The alternative is: Step 1, move supraneural 2 to between neural spines 1 and 2; Step 2, move supraneural 3 to between neural spines 1 and 2; Step 3, remove $1^{\text {" }}$ pterygiophore; Step 4, remove $2^{\text {nd }}$ pterygiophore; Step 5, remove $3^{\text {rd }}$ pterygiophore; Step 6, gain additional pterygiophore between neu al spines 3 and 4 . Thus, the first transformation comprises four movements and two losses, whereas the alternative comprises two movements, three losses and one addition.

\section{Reproductive biology}

The gonads of each fish retained from the Murchison River were examined, and the sex and stage of gonadal development determined macroscopically. The stage of gonadal development was based on the following criteria adapted from Laevastu (1965): stage I/II (immature); stages III/IV (maturing); stage V (mature); stage VI (spawning) and stage VII (spent or recently spawned).

\section{RESULTS}

\section{Environmental variables}

The mean water temperature at the main study sites followed a seasonal pattern, peaking in February ( $\mathrm{ca} 27^{\circ} \mathrm{C}$ ) and reaching a minimum in August (ca $16^{\circ} \mathrm{C}$ ) 2001 . The conductivity of the main study sites throughout the year of the study ranged from $1.6-26.8 \mathrm{mScm}^{-1}$, but averaged ca 13.2 $\mathrm{mScm}^{-1}$.

\section{Distribution of terapontids in the Murchison River}

Terapontids were captured at 13 sites in the Murchison River. Forms that superficially more closely resembled $L$. unicolor were found at all sites except the two most downstream locations (Figure 3 ). Those resembling more closely $A$. caudavittata were captured at nine sites, ranging from the two downstream sites to the most inland sites. Both 'forms' co-occurred at seven sites.

\section{Morphology and osteology}

Of the 231 terapontids examined for vertebral and first dorsal osteological comparison during this study, 32 different patterns were evident (Figures 2 and 4 , Table 1 ).

In the Murchison River samples collected during the current study, only $24(30 \%)$ of the 80 individuals that superficially more closely resembled $L$. unicolor had an osteological configuration that complies with Vari's (1978) description for Leiopotherapon (see also Figures 2 and 4). In the remaining 56 individuals, 20 different osteological patterns unlike those described for any other terapontid, were found (Figure 4, Table 1). The most common of these variant configurations (Type 4, 20 individuals) differs from the configuration diagnostic of Leiopotherapon only in having the second pterygiophore arising from between the second and third, rather than the third and fourth, neural spines (Figure 4, Table 1). Of the remaining configurations present in specimens that resembled $L$. unicolor, types $1,2,3$, and 5 also vary from the pattern diagnostic of Leiopotherapon in only requiring the addition or movement of a supraneural or pterygiophore and its spine, whilst Type 7 only requires the addition of a supraneural 
Type $1-L u$

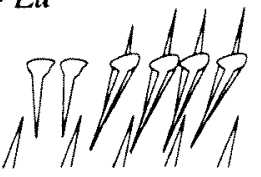

Type 2 - $L u$

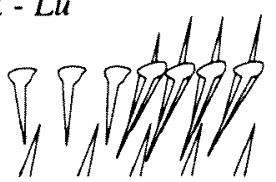

Type 3 - $L u$

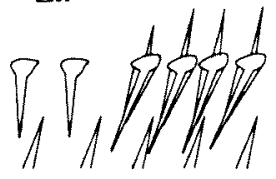

Type 4 - $L u$

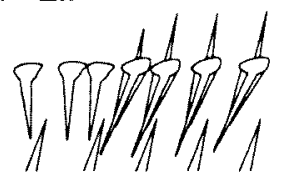

Type 5 - $L u$

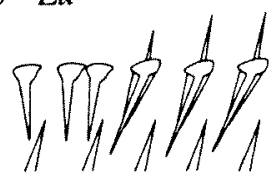

Type $6-A c$

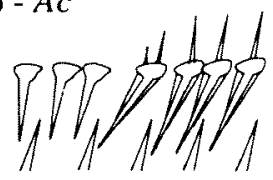

Type 7 - $L u$

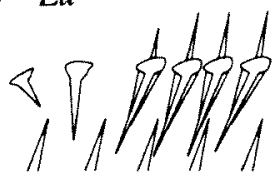

Type 8 - $L u$

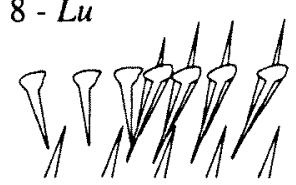

Type $9-L u$

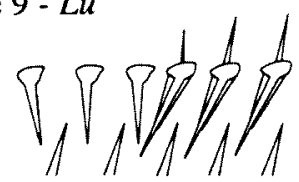

Type $10-L u$

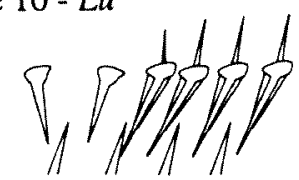

Type $11-L u \& A c$

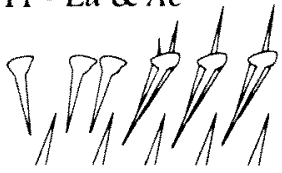

Type $12-L u$

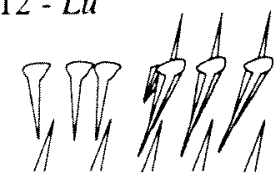

Type $13-L u$

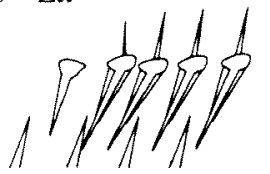

Type $14-L u$

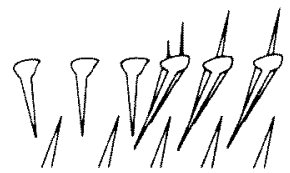

Type $15-L u$

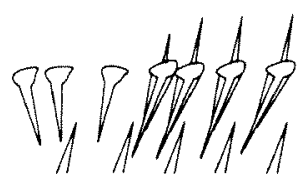

Type $16-A c$

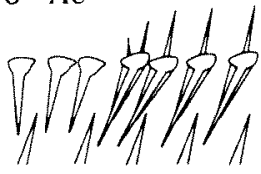

Type 17 - $L u$

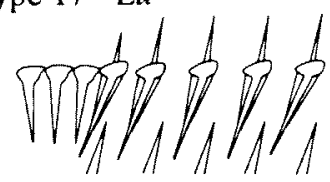

Type 18 - $L u$

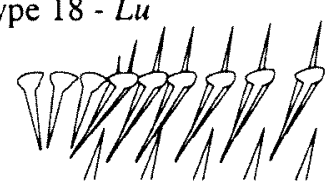

Type 19 - Lu

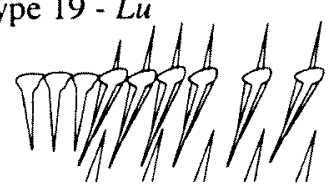

Type 20 - Lu

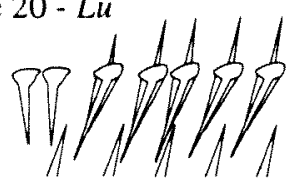

Type 21 - Lu

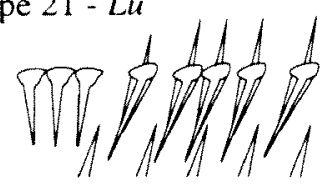

Type $22-L u$

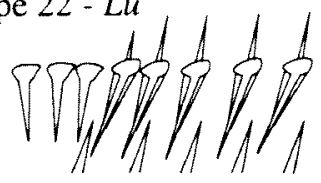

Type $23-L u$

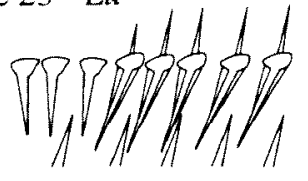

Type $24-A c$

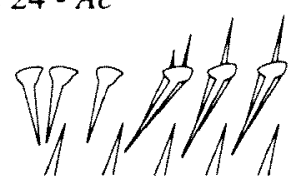

Type $25-L u$

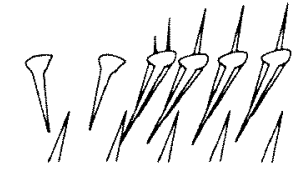

Type $26-A c$

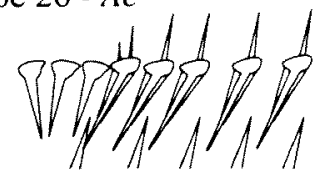

Type 27 - AC

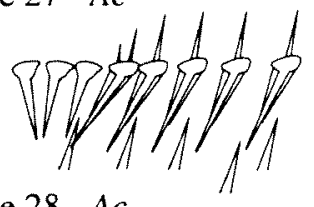

Type 28 - Ac

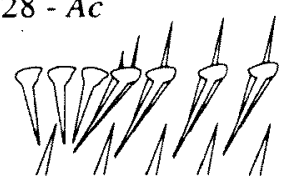

Type 29 - $L u \& A c$

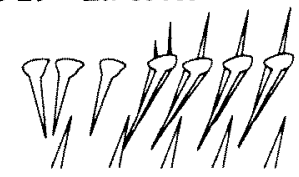

Type $30-A c$

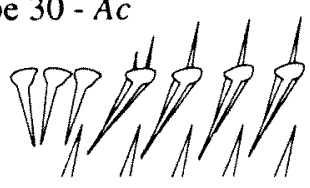

Figure 4 Diagramatic representation of the osteology of the anterior section of the first dorsal fin for the teraponids examined and whether they superficially resembled Leiopotherapon unicolor $(L u)$ or Amniataba caudavittata $(A c)$. 
and a slight increase in the size of the first supraneural. The remaining patterns (types 8,10 , $12,13,15,17-23,25$ and 29) require between two and six transformation steps. Of these patterns, types $1-5,7,8,10,12$ and 13 are closer to the pattern diagnostic of Leiopotherapon, types 18-23, 25 and 29 are closer to that of Amniataba, and types 15 and 17 are equidistant between the two.

Of the 52 individuals that superficially more closely resembled $A$. caudavittata, 42 (ca $81 \%$ ) had the osteological pattern characteristic for that genus (Figure 2) (Vari 1978), however, the remaining 10 (ca 19\%) displayed nine different osteological configurations unlike those described for any other terapontid (types 6, 11, 16, 24 and 26-30 in Figure $4)$. Three patterns (28-30) are only one transformation step from that diagnostic of Amniataba, whilst the remainder are either two (types 16, 24, 26 and 27) or three (types 6 and 11) steps away. Of these patterns, types 24 and 26-30 are closer to the pattern diagnostic of Amniataba, types 6 and 11 are closer to that of Leiopotherapon, and Type 16 is equidistant between the two.

Of the $L$. unicolor examined from the collections of the Western Australian Museum, and that all superficially resembled that species, two specimens from 1958 (P4336) conformed to the diagnostic pattern of the genus and the remaining two were of the Type 2 pattern, i.e., one step from the diagnostic pattern, whilst two specimens from 1961 (P5362) were Type 4 and the other was Type 10, i.e., one and two steps from the diagnostic pattern, respectively (Figures 1 and 2, Table 1). All of these patterns are closer to that diagnostic of Leiopotherapon rather than that of Amniataba.

Of the five $L$. unicolor examined from the Gascoyne River, one conformed to Vari's (1978) description, whilst the others were types 4 (2) and 2 (2), patterns that are both only one transformation step away from the diagnostic pattern. All four of the presumptive $L$. unicolor from the Minilya River had a dorsal osteological pattern unlike that described by Vari (1978), one of these had a Type 2 pattern (one step from the diagnostic pattern) that was also found in fish from the Murchison and Gascoyne Rivers, one had a Type 9 pattern (two steps) and the remaining two individuals had a Type 14 configuration (three steps), these latter patterns were unlike any of the other individuals examined (Figure 4, Table 1). One of the five individuals from the Cane River conformed to $L$. unicolor, whilst the remaining four all exhibited the Type 4 pattern (one step). In the specimens from the Yule River, three individuals had the pattern diagnostic of $L$. unicolor, one had a Type 4 and one a Type 12 pattern, i.e. one and three steps away from the diagnostic pattern, respectively (Figures 2 and 4 , Table 1 ). Of the five $L$. unicolor examined in the De Grey River, two conformed to Vari's (1978) description, two were Type 4 (one step) and one was Type 11 (two steps). Of the five L. unicolor examined from the Fitzroy River one followed Vari (1978), while the others were types 4 (two, one step), 11 (one individual, two steps) or 15 (one, two steps). The Type 11 pattern was also found in a fish from the Murchison River, but in that case the individual more closely resembled Amniataba (Figure 4, Table 1). All of these patterns are equal (Type 15) or closer to that diagnostic of Leiopotherapon rather than that of Amniataba.

All $A$. caudavittata examined from the Swan River (5) and Shark Bay (25), and 30 of 33 examined from Cape Keraudien had a dorsal osteology that conformed to Vari's (1978) description for Amniataba. The three individuals that differed in osteological formula from Vari's (1978) description were either types 28 (1) or 30 (2). Both of these patterns only require the movement of a single supraneural to conform to the Vari's (1978) diagnosis for Amniataba (Figures 1 and 4, Table 1).

Based on comparisons of the minimum number of steps required for a pattern to transform into those diagnostic of Leiopotherapon and Amniataba, the fish that superficially more closely resembled $L$. unicolor bore 13 patterns that were more similar to the diagnostic configuration for Leiopotherapon (i.e., types 1-5 and 7-14), eight that were more similar to that diagnostic for Amniataba (i.e., types 18-23, 25 and 29), whilst two are equidistant between the two diagnostic patterns (i.e., types 15 and 17) (Figures 2 and 4, Table 1). In the case of fish resembling $A$. caudavittata, there were five patterns that more closely resembled that diagnostic for Amniataba (i.e., types 24, 26-28 and 30), two were more similar to that of Leiopotherapon (i.e., types 6 and 11) and the remaining pattern was equidistant between the two (i.e., Type 16) (Figures 2 and 4, Table 1).

Vari (1978) noted that Leiopotherapon and Amniataba can be distinguished by the following osteological criteria: one supraneural bone in front of the first neural spine in Leiopotherapon versus two in Amniataba; one spine on the first dorsal pterygiophore versus two; the insertion of the first proximal dorsal pterygiophore between the second and third neural spines versus its insertion between the first and second; two of the anterior proximal dorsal pterygiophores inserting between successive neural spines versus one. In the current study, of the individuals that superficially most closely resembled $L$. unicolor, six had two supraneurals in front of the first neural spine (types 15 (3), 20, 23 and 29), five had two spines (types 14 (2), 18, 25 and 29), seven had the first proximal dorsal pterygiophore inserting between the first and second neural spines (types 20, 21 (4), 22 and 23) and six individuals had only one of the anterior proximal dorsal pterygiophores inserting between 


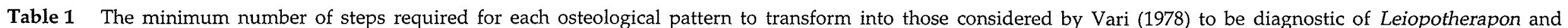
Amniataba. Possible character transforms are provided, with $\mathrm{SN}=$ supraneural, $\mathrm{PT}=$ pterygiophore, $\mathrm{NS}=$ neural $s$ pine and $\mathrm{FR}=$ fin ray. $\mathrm{N} . \mathrm{B}$. Where more than one set of character transformations are possible only one example is provided (see text for examples of other equally parsimonious transfomation patterns). $M=$ Murchison River fish this study; WAM = Murchison River fish from the collections of WAM; $G=$ Gascoyne River; Mi = Miniliya River; $C=C a n e$ River; $Y=Y u l e$ River; $\mathrm{DG}=$ De Grey River; F = Fitzroy River; $\mathrm{S}=$ Swan River; $\mathrm{SB}=$ Shark Bay; $\mathrm{CK}=$ Cape Keraudien. Normal font indicates fish that superficially most closely resembled $L$. unicolor, italics represents fish that most closely resembled $A$. caudavittata.

\begin{tabular}{|c|c|c|}
\hline $\begin{array}{l}\text { Osteological } \\
\text { pattern }\end{array}$ & Steps to Leiopotherapon & Steps to Amniataba \\
\hline Type $1(1, M)$ & 1 - additional SN anterior to NS 1. & $\begin{array}{l}5-1^{\text {st }} \text { SN to anterior of NS 1; additional SN anterior to NS } 1 \text {; PT } 1 \text { to between NS } 1 \& 2 \text {; } \\
\text { additional FR on PT 1; additional PT between NS } 3 \& 4 \text {. }\end{array}$ \\
\hline $\begin{array}{l}\text { Type } 2(5, \mathrm{M} ; 2, \\
\text { WAM; } 2, \mathrm{G} ; 1, \mathrm{Mi})\end{array}$ & $1-$ SN 3 to between NS $1 \& 2$ & $\begin{array}{l}5 \text { - SN } 2 \text { to anterior of NS } 1 \text {; SN } 3 \text { to between NS } 2 \text { \& } 3 \text {; PT } 1 \text { to between NS } 2 \text { \& } 3 \text {; } \\
\text { additional FR on PT 1; rem. } 2^{\text {nd }} \text { or } 3^{\text {rd }} \text { PT. }\end{array}$ \\
\hline Type $3(3, \mathrm{M})$ & 1 - additional SN anterior to NS 2. & $\begin{array}{l}\text { 4- additional SN anterior to NS 1; PT } 1 \text { to between NS } 1 \& 2 \text {; additional FR to PT } 1 \text {; PT } 2 \text { to } \\
\text { between NS } 2 \text { \& } 3 \text {. }\end{array}$ \\
\hline $\begin{array}{l}\text { Type } 4(20, M ; 2, \\
\text { WAM; } 2, G ; 4, C ; \\
1, Y ; 2, D G ; 2, F)\end{array}$ & 1 - PT 2 to between NS $3 \& 4$ & 3-SN 2 to anterior of NS 1; PT 1 to between NS 1 \& 2; additional FR on PT 1. \\
\hline Type $5(2, M)$ & 1 - additional PT between NS $3 \& 4$ & 3 - SN 2 to anterior of NS 1 ; add PT between NS 1 \& 2; additional FR on new PT 1. \\
\hline Type $6(1, M)$ & 1 - rem. FR on PT 1. & 3 - SN 2 to anterior of NS 1 ; PT 1 to between NS $1 \& 2 ; \mathrm{PT} 2$ to between NS $2 \& 3$. \\
\hline Type $7(1, \mathrm{M})$ & 2 - inc. size of SN 1 ; additional SN between NS $1 \& 2$. & $\begin{array}{l}5 \text { - inc. size of SN } 1 \text {; additional SN anterior of NS } 1 \text {; PT } 1 \text { to between NS } 1 \text { \& } 2 \text {; additional } \\
\text { FR on PT 1; PT } 2 \text { to between NS } 2 \text { \& } 3 \text {. }\end{array}$ \\
\hline Type $8(1, M)$ & 2 - SN 3 to between NS 1 \& 2; PT 2 to between NS 3 \& 4. & $\begin{array}{l}4-\text { SN } 2 \text { to anterior of NS } 1 \text {; SN } 3 \text { to between NS } 1 \text { \& 2; PT } 1 \text { to between NS } 1 \& 2 \text {; } \\
\text { additional FR on PT } 1 .\end{array}$ \\
\hline Type $9(1, \mathrm{Mi})$ & 2 - SN 3 to between NS $1 \&$ 2; additional PT between NS $3 \& 4$ & $\begin{array}{l}4-\text { SN } 2 \text { to anterior of NS } 1 \text {; SN } 3 \text { to between NS } 1 \& 2 \text {; additional PT between NS } 1 \text { \& } 2 \text {; } \\
\text { additional FR on new PT } 1 \text {. }\end{array}$ \\
\hline $\begin{array}{l}\text { Type } 10(6, M ; 1 \\
\text { WAM) }\end{array}$ & 2 - additional SN between NS $2 \& 3:$ PT 2 to between NS $3 \& 4$. & 3 - additional SN anterior to NS 1; additional FR on PT 1; PT 1 to between NS $1 \& 2$. \\
\hline $\begin{array}{l}\text { Type } 11(1, \mathrm{DG} ; 1 \\
\mathrm{F} ; 1, M)\end{array}$ & 2 - rem. FR on PT 1 ; additional PT between NS $3 \& 4$ & 3 - SN 2 to anterior of NS 1; PT 1 to between NS 1 \& 2; additional PT between NS 2 \& 3. \\
\hline Type $12(1, M ; 1, Y)$ & 3 -inc. size of PT 1; add FR to PT 1; PT 2 to between NS 3 \& 4. & 5 -SN 2 to anterior of NS 1 ; inc. size of PT 1 ; PT 1 to between NS $1 \& 2$; add 2 FRs to PT 1. \\
\hline Type $13(2, \mathrm{M})$ & $\begin{array}{l}3 \text { - additional SN anterior to NS } 1 \text {; additional SN between } \\
\text { NS } 2 \text { \& } 3 \text {; PT } 2 \text { to between NS } 3 \& 4 \text {. }\end{array}$ & 4 - additional 2 SNs anterior to NS 1; PT 1 to between NS 2 \& 3; additional FR on PT 1. \\
\hline Type $14(2, \mathrm{Mi})$ & $\begin{array}{l}3-\text { SN } 3 \text { to between NS } 1 \text { \& } 2 \text {; rem. FR on PT 1; additional } \\
\text { PT between NS } 3 \& 4 \text {. }\end{array}$ & $\begin{array}{l}4-\text { SN } 2 \text { to anterior of NS } 1 \text {; SN } 3 \text { to between NS } 1 \text { \& 2; PT } 1 \text { to between NS } 1 \text { \& } 2 \text {; } \\
\text { additional PT to between NS } 2 \& 3 \text {. }\end{array}$ \\
\hline Type $15(2, \mathrm{M} ; 1, \mathrm{~F})$ & 2 -SN 2 to between NS $1 \& 2 ;$ PT 2 to between NS $3 \& 4$. & 2 - PT 1 to between NS 2 \& 3; additional FR on PT 1. \\
\hline
\end{tabular}


Type $16(1, M)$

Type $17(1, \mathrm{M})$

Type $18(1, M)$

Type $19(1, M)$

Type $20(1, \mathrm{M})$

Type $21(4, M)$

Type $22(1, \mathrm{M})$

Type $23(1, M)$

Type $24(1, M)$

Type $25(1, M)$

Type $26(1, M)$

Type $27(1, M)$

Type 28 (1, M; 1 , CK)

Type $29(1 \mathrm{M} ; 1, M) 3-\mathrm{SN} 2$ to between NS $1 \& 2$; rem. FR on PT 1 ; PT 2 to between NS $3 \& 4$.

Type $30(2, M ; 2, \quad 4-$ SN 2 to between NS 1 \& 2; SN 3 to between NS 1 \& 2; CK)

2 - rem. FR on PT 1; PT 2 to between NS $3 \& 4$.

$4-$ SN 2 to between NS $1 \&$ 2; SN 3 to between NS $1 \& 3$; rem. $1^{\text {st }} \mathrm{PT}$; rem. $2^{\text {nd }} \mathrm{PT}$.

5 - SN 1 to between NS $1 \& 2 ;$ SN 2 to between NS $1 \& 2 ;$ rem. $1^{\text {st }}$ PT; rem. $2^{\text {nd }}$ or $3^{\text {rd }}$ PT; new PT 1 to between NS $2 \& 3$.

6 - SN 2 to between NS $1 \& 2 ;$ SN 3 to between NS $1 \& 2$. rem. $1^{\text {st }} \mathrm{PT}$; rem. $2^{\text {nd }}$ or $3^{\text {rd }} \mathrm{PT}$; new PT 1 to between NS $2 \& 3$; new PT 2 to between NS $3 \& 4$.

$4-2^{\text {nd }}$ SN to between NS $1 \& 2$; additional SN between NS $1 \& 2$; rem. PT 1; new PT 2 to between NS $3 \& 4$.

$4-$ SN 2 to between NS 1 \& 2; SN 3 to between NS 1 \& 2 ; rem. $1^{\text {sl }}$ PT; new PT 2 to between NS $3 \& 4$.

- SN 2 to between NS 1 \& 2; SN 3 to between NS $1 \& 2$ rem. $1^{\text {st }}$ or $2^{\text {nd }} \mathrm{PT}$; (new) PT 1 to between NS 2 \& 3 ; (new) PT to between NS $3 \& 4$

3 - SN 2 to between NS $1 \& 2 ;$ rem. $1^{\text {st }}$ PT new PT 2 to between NS $3 \& 4$.

3 - SN 2 to between NS 1 \& 2 ; rem. FR on PT 1 ; additional PT between NS $3 \& 4$.

3 - additional SN between NS 2 \& 3; lose FR 1 on PT 1 ; PT 2 to between NS $3 \& 4$.

5 - SN 2 to between NS $1 \& 2 ;$ SN 3 to between NS $1 \& 2$ rem. $1^{\text {st }} \mathrm{PT} ; 2^{\text {nd }} \mathrm{PT}$ to between NS $2 \& 3 ; 3^{\text {rd }} \mathrm{PT}$ to between NS 3 \& 4

6 - Same as Type 27, plus increase size of NS 4.

rem. PT 1; additional PT between NS 3 \& 4
2 - SN 2 to anterior of NS 1; PT 1 to between NS $1 \& 2$.

4 - SN 3 to between NS 1 \& 3; rem. $1^{\text {st }}$ or $2^{\text {nd }}$ PT; remaining PT to between NS 1 \& 3; additional FR on PT 1.

4-SN 3 to between NS 1 \& 2; PT to between NS 1 \& 2; rem. $2^{\text {nd }} \mathrm{PT} ;$ rem. $3^{\text {rd }} \mathrm{PT}$.

4 - SN 3 to between NS 1 \& 2 ; rem. $1^{\text {st }}$ PT; rem. $2^{\text {nd }}$ or $3^{\text {rd }}$ PT; additional FR on new PT 1.

3 - additional SN between NS $1 \& 2$; additional FR to PT 1 ; rem. $2^{\text {nd }}$ or $3^{\text {rd }} \mathrm{PT}$.

3 - SN 3 to between NS 1 \& 2; additional FR on PT 1; rem. $2^{\text {nd }}$ or $3^{\text {rd }}$ PT.

3 - SN 3 to between NS $1 \& 2$; rem. $1^{\text {st }}$ or $2^{\text {nd }}$ PT; additional FR on new PT 1.

2 - additional FR on PT 1; rem. $2^{\text {nd }}$ or $3^{\text {rd }}$ PT.

2 - PT 1 to between NS 1 \& 2; additional PT between NS 2 \& 3.

2 - additional SN anterior to NS 1; PT 1 to between NS $1 \& 2$.

2 - SN 3 to between NS 1 \& 2; rem. $2^{\text {nd }} \mathrm{PT}$.

2 - Same as Type 27, plus increase size of NS 4.

1 - SN 2 to anterior of NS 1 .

$1-$ PT 1 to between NS $2 \& 3$.

$1-$ SN 3 to between NS $1 \& 2$ 
successive neural spines (types 5 (2), 9, 14 (2) and 17). In the case of individuals that superficially most closely resembled $A$. caudavittata, five had only one supraneural in front of the first neural spine (types $6,11,16$ and 28 (2)), four had the first proximal dorsal pterygiophore inserting between the second and third neural spines (types 6, 11, 16 and 24) and four individuals had two of the anterior proximal dorsal pterygiophores inserting between successive neural spines (types 6, 16, 26 and 27). All individuals that superficially resembled $A$. caudavittata had two spines on the first dorsal pterygiophore.

\section{Reproductive biology}

Individuals exhibiting characteristics of both species had lengths ranging from $39-253 \mathrm{~mm}$ TL, while those representing $L$. unicolor and $A$. caudavittata ranged in length from 47-211 and 29$206 \mathrm{~mm}$, respectively. Of the 13 fish greater than $200 \mathrm{~mm}$ TL, 11 exhibited characteristics of both species.

From the macroscopic staging of the gonads of all fish dissected, including those with characteristics of both species, it was evident that many were either mature, spawning or had recently spawned. The peak spawning period for the two species and the fish exhibiting characteristics of both species in the Murchison River appeared to be in late summer/ early autumn.

The sex ratio in the individuals that exhibited both characteristics was ca 1.8 females: 1 male, whereas for $L$. unicolor and $A$. caudavittata it was $2: 1$ and $1.6: 1$, respectively.

\section{DISCUSSION}

Of the 161 terapontids collected from the riverine sites during the current study, the characteristics of the first dorsal/neural spine matrix resembled $L$. unicolor in about $20 \%$ of cases and $A$. caudavittata in about $26 \%$ of cases. The remaining $54 \%$ of fish had first dorsal/neural spine osteological characteristics unlike any of those described for terapontids by Vari (1978). Whilst many of the novel patterns described in the current study are very similar to those described by Vari (1978) as diagnostic for the two genera, others bear little resemblance to the diagnostic patterns. Vari (1978), who examined 10 specimens from the Murchison River, 76 from the De Grey River and over 100 from the Fitzroy River, made no mention of the osteological variability evident in the current study for these species. Furthermore, he noted no variation in the patterns of other members of these genera considering the two patterns to be diagnostic for Leiopotherapon and Amniataba. Although it is not known how many individual $L$. unicolor or A. caudavittata, or specimens of other species within these two genera, Vari radiographed or cleared and stained for osteological examination (Vari personal communication), given such a high occurrence of different pterygiophore patterns (i.e., $54 \%$ were unusual), it could be expected that he would have noticed some exceptions. However, our preliminary use of radiographs suggested that it was often difficult to discern minor variations in pattern using this method. Thus, although not noted by Vari (1978), it is likely that some minor natural variations in pterygiophore pattern occur in these species. For example, of the 63 specimens of $A$. caudavittata examined from the Swan River, Shark Bay and Cape Keraudien, i.e., estuarine and marine sites at which $L$. unicolor does not exist, the three that did not conform to the pattern diagnostic for that genus only differed in the position of the second or third supraneural. Furthermore, although variations in pterygiophore pattern were evident in some specimens of $L$. unicolor examined from the Western Australian Museum, these variations were minor and all specimens exhibited the coloration of that species.

Notwithstanding that some minor differences in the anterior dorsal-fin pterygiophore pattern occur naturally, the level of variation in the first dorsal/ neural spine patterns and the fact that many specimens exhibited coloration and shape characteristics of both $L$. unicolor and $A$. caudavittata suggests that in the Murchison River these two species can readily hybridise. This is further highlighted by the fact that in many instances it was very difficult to decide whether fish superficially resembled $L$. unicolor or $A$. caudavittata. Furthermore, as only seven of the 25 presumptive $L$. unicolor examined from the Minilya, Cane, Yule, De Grey and Fitzroy Rivers were actually $L$. unicolor as described by Vari (1978), and as each river had at least two specimens that did not conform to the diagnostic pattern, it is possible that hybridisation between terapontids is not restricted to the Murchison River. It is also worth noting that the related barred grunter (Amniataba percoides) is present in some of these rivers and that Dr Barry Hutchins of the Western Australian Museum believes that hybridisation between terapontids may be quite common in the rivers of the Kimberley (Hutchins pers. com., see also Hutchins 1981).

In addition to proposing that much of the variation in coloration and anterior pterygiophore patterns described in the current study is the result of hybridisation, we also suggest that, in the Murchison River at least, (1) hybridisation has been occurring for at least the last few breeding seasons, (2) hybrids are reproductively viable and (3) some individuals may have been hybrids of hybrids. These further hypotheses are based on the facts that fish from the Murchison River that exhibited such 
variations included, several distinct size-classes (length-range 39-253 mm TL), individuals that had spawned or were spawning and individuals with configurations very different and not intermediate to the parent species (see Campton 1987, 1991).

In considering Campton's (1987) criteria that increase the likelihood of hybridisation, it is evident that, (1) competition for spawning sites, (2) weak ethological isolating mechanisms, (3) unequal abundance of parent species and (4) susceptibility to secondary contact between recently evolved forms, may all be applicable when considering why hybridisation of $L$. unicolor and $A$. caudavittata apparently occurs so readily in the Murchison River. For example, (1) the river is generally narrow, its waters shallow (generally $<2 \mathrm{~m}$ deep), with spawning sites likely to be in the algal beds that characterise the littoral zones. Furthermore, spawning activity of both species overlaps and is confined to the warmer summer/autumn months (see also Beumer 1979; Potter et al. 1994 for spawning periods of these species in other systems), when the river may be comprised of small disconnected pools. (2) Both species readily school together, grow to a similar size, and have a similar diet (Morgan unpublished data). (3) Initially, $L$. unicolor may have been the dominant species, however, as salinity increased during land clearing in the middle catchment, $A$. caudavittata may have been drawn further upstream, thereby (4) facilitating secondary contact between recently evolved forms, which may not have developed mechanisms to isolate the species when sympatric (Hubbs 1961).

In regards to points (3) and (4) above it is pertinent to note that whilst $A$. caudavittata is essentially a marine/estuarine species, an increase in the salinity of previously freshwater stretches may have enabled this species to colonise a large proportion of Murchison River catchment. Such an increase in the salt content of previously freshwater stretches is likely the result of the large scale land clearing that has occurred in the middle of the catchment, a situation not uncommon in Western Australia. For example, in south-western Western Australia, where salinities in many rivers (e.g., Swan-Avon River, Blackwood River) have increased greatly as a result of excessive land clearing, a number of estuarine species are now entrenched in the waters a long distance from their normal estuarine environ (e.g., Western Hardyhead Leptatherina wallacei and the goby Pseudogobius olorum) (Morgan et al. 1998, 2003; Morgan and Gill 2000). Although Amniataba caudavittata has not yet moved long distances inland in any of the rivers of south-western Western Australia, it is found a considerable distance inland in the salt-affected Greenough River (Figure 3, Morgan and Gill 2004).

In summary, we believe that the results of the current study support the view that, in the Murchison River at least, $L$. unicolor and $A$. caudavittata hybridised. We further propose that the considerable differences in the osteology of these hybrids compared with the parent species, their dominance in terms of numbers and the fact that many had recently spawned indicate that they are reproductively viable. Increases in the salinity of the Murchison River (through land clearing) are likely to have permitted the upstream movement of the marine/estuarine $A$. caudavittata into areas previously only inhabited by $L$. unicolor. Once these species became sympatric, the considerable overlap in spawning period, similarity in habitat utilisation, behaviour and diets, as well as their restriction to small pools during the summer spawning period would enhance the likelihood of hybridisations occurring. Genetic studies would be useful in verifying that the intermediary forms described in the current study are indeed hybrids, whilst further reproductive studies would allow us to determine the viability of such hybrids. If genetic studies confirm that these intermediary forms are hybrids, the examination of the osteological characteristics from museum specimens and other rivers could then be used to determine whether hybridisation is a recent phenomenon that is facilitated by increasing salinity levels and if is occurring between terapontids in other river systems of Australia. The collection of these genetic, and spatial and temporal data is crucial. If, as we suspect, the increase of salinities in our rivers has facilitated hybridisation by removing an isolating barrier, then the effect of salinisation is far more insidious than merely the loss of habitat available to freshwater species, it may result in the loss of species through their replacement by hybrids.

\section{ACKNOWLEDGEMENTS}

Thanks to the Natural Heritage Trust, Department of Fisheries Western Australia, Water and Rivers Commission Western Australia and Murdoch University for providing funds for the project. Thanks to the Department of Conservation and Land Management for providing access to the Kalbarri National Park. Thanks to Charlotte Morgan, Stephen Beatty, Mark Allen and Steven Head for help in the collection of fish.

\section{REFERENCES}

Allen, G.R., Midgley, S.H. and Allen, M. (2002). Field Guide to the Freshwater Fishes of Australia. Western Australian Museum, Perth.

Beumer, J.P. (1979). Reproductive cycles of two Australian freshwater fishes: the spangled perch, Therapon unicolor Gunther, 1859 and the East Queensland rainbowfish, Nematocentris splendida Peters, 1866. Journal of Fish Biology 15: 111-134. 
Campton, D.E. (1987). Natural hybridization and introgression in fishes - methods of detection and genetic interpretations. In N. Ryman and F. Utter (eds), Population Genetics \& Fishery Management, pp. 162-192. University of Washington Press, Seattle.

Campton, D.E. (1991). Application of biochemical and molecular genetic markers to analysis of hybridization. In D.H. Whitmore (ed.), Electrophoretic and Isoelectric Focusing Techniques in Fisheries Management, pp. 241-263. CRC Press, Boston.

Hubbs, C.L. (1961). Isolating mechanisms in the speciation of fishes. In W.F. Blair (ed.), Vertebrate Speciation, pp. 5-23. University of Texas Press, Austin.

Hutchins, J.B. (1981). Freshwater fish fauna of the Mitchell Plateau Area, Kimberley, Western Australia. In, Biological survey of Mitchell Plateau and Admiralty Gulf, Kimberley, Western Australia. Western Australian Museum, Perth.

Hutchins, B. and Swainston, R. (1986). Sea Fishes of Southern Australia. Swainston Publishing, Perth.

Laevastu, T. (1965). Manual of Methods in Fisheries Biology. FAO, Rome.

Morgan, D.L. and Gill, H.S. (2000). Fish associations within the different inland habitats of lower southwestern Australia. Records of the Western Australian Museum 20: 31-37.

Morgan, D.L. and Gill, H.S. (2004). Fish fauna in inland waters of the Pilbara (Indian Ocean) Drainage Division of Western Australia - evidence for three subprovinces. Zootaxa 636: 1-43.

Morgan, D.L., Gill, H.S. and Potter, I.C. (1998). Identification, distribution and biology of the freshwater fishes in south-western Australia. Records of the Western Australian Museum, Supplement 56: 1-97.
Morgan, D.L., Thorburn. D.C. and Gill, H.S. (2003). Salinization of south-western Western Australian rivers and the implications for the inland fish fauna the Blackwood River, a case study. Pacific Conservation Biology 9: 161-171.

Nelson, J.S. (1994). Fishes of the World. 2nd edn. J. Wiley, New York.

Potter, I.C., Neira, F.J., Wise, B.S. and Wallace, J.H. (1994). Reproductive biology and larval development of the terapontid Amniataba caudavittata, including comparisons with the reproductive strategies of other estuarine teleosts in temperate Western Australian. Journal of Fish Biology 45: 57-74.

Schwartz, F.J. (1972). World literature to fish hybrids, with an analysis by family, species, and hybrid. Publications of the Gulf Coast Research Laboratory Museum 3: 328pp.

Schwartz, F.J. (1981). World literature to fish hybrids, with an analysis by family, species, and hybrid: supplement 1, NOAA technical report. NMFS SSRF. 750. Washington DC: US Department of Commerce.

Vari, R.P. (1978). The terapon perches (Percoidei, Teraponidae). A cladistic analysis and taxonomic revision. Bulletin of the American Museum of Natural History 159 (5): 175-340.

Wise, B.S., Potter, I.C. and Wallace, J.H. (1994). Growth, movements and diet of the terapontid Amniataba caudavittata in an Australian estuary. Journal of Fish Biology 45: 917-931.

Manuscript received 12 November 2003; accepted 16 September 2005 